These experiences were re-enforced by the abuse of psychiatry to silence political opponents in the former East Germany.

Without the experience of totalitarian dictatorship and abuse Great Britain chooses a very pragmatic approach towards involuntary hospitalisation and treatment assuming that experts and relatives act benevolently in the patient's interest. From a German point of view it is remarkable that in Great Britain experts have rights in decision-making processes. Decisions can be made by social workers, community psychiatric nurses, doctors and relatives, whereas in Germany courts have the decision monopoly. In Britain the function of the courts is that of control rather than of decision-making itself.

Theoretically, the German model has the advantage that a body completely independent of the medical institutions makes decisions, thus avoiding the impression of a possible conflict of interest. However, this theoretical advantage is very often not felt by the patient because of the complexity of the regulations and the big distance between the court and the hospitalised patient. Furthermore the highly formalised procedures themselves can bring about controversy and polarisation which are therapeutically undesirable.

The British model on the other hand has the advantage of an individual approach with the integration of family and carers in the decisionmaking process, as well as the hospital or the home being the location of the decision-making. However, the instrument of second opinions as instance of control puts the experts involved under a high moral and professional obligation and responsibility.

It is impossible to answer the question in which way the interests of the mentally ill are better served. Studies in the USA show the importance of the feeling that hospitalisation occurred in a fair process and is comprehensible for therapy motivation and post-discharge compliance (Lidz et al, 1995) so that the problem should not be ignored. Thus, comparative European studies about the way that sectioned patients perceive their hospitalisation and treatment would be highly desirable, with Britain and Germany being ideal locations to do this because of their different medico-legal approach.

\section{References}

DEuTsCH, E. (1991) Arzt- und Arzneimittelrecht (Medical and pharmaceutical law issues). Berlin. Heidelberg \& New York: Springer-Verlag.

EBERHARD, G. A. (1988) Hifen, Schutzmaßnahmen und Maßregelvollzug bet psychischen Krankhetten in Nordrhein-Westfalen: Handbuch PsychKG-MRVGKommunale Schriften für Nordrhein-Westfalen, Band 19. (Commentary on the Northrine-Westphalian sectioning law). Cologne: Deutscher Gemeindeverlag.

LIDZ, C. W., HOGE, S. K., GARDNER, W., et al (1995) Percetved coercion in mental hospital admissions. Archives of General Psychiatry, 62, 1034-1039.

RiEdel, R. R. SEIDL, H., HOFF, P., et al (1992) Zwangsbehandlung gegen den Willen des Patienten in der Psychiatrie (Forced treatment of psychiatric patients). Münchener Medizinische Wochenschrift, 92. 33-37.

RUDOLF, G. A. E. \& RótTGERS, H. R. (1997) Rechtsfragen in der Psychiatrie (Law issues in psychiatry). Wiesbaden: Deutscher Universitaetsverlag.

Hanns Rüdiger Röttgers, Public Health Authority, Psychiatric Department County of Verden/Lower Saxony, Lindhooper Straße 67, D-27283, Verden Aller; and Peter Lepping, Wirral and West Cheshire Community NHS Trust, West Cheshire Hospital, Liverpool Road, Chester CH2 1UL

\title{
Is specialist registrar training in cognitive therapy effective?
}

\author{
Steve Moorhead and Jan Scott
}

\begin{abstract}
Alms and method This paper describes the characteristics and outcome of the first 20 patients seen by a newly appointed specialist registrar in cognitive therapy. The outcome of the first (cases 110) and second (cases 11-20) cohorts were evaluated to assess if training had any impact on clinical effectiveness.
\end{abstract}

Results Comorbidity was common, but more patients improved following the intervention (effect size $=0.64-1.34$ ). The $25 \%$ therapy drop-out rate was comparable with previlously reported rates. Four out of five patients who dropped out had Cluster B personality disorders. The two cohorts showed similar baseline characteristics, but the second cohort showed 
improved outcome (effect stze of training $=0.89-1.04$ ) and had a significantly shorter course of therapy $(P=0.02)$. Clinical implications Speciallst registrar training in cognitive therapy provides experience in treating a wide variety of mental disorders. The routine collection and analysis of clinical and psychometric data helps ldentify training effectiveness and training needs. The data demonstrate that training was associated with improved patient outcomes.

There is an increasing demand within the National Health Service (NHS) for short-term evidence-based psychotherapies such as cognitive therapy. The need for training in cognitive therapy led to the development of four new specialist registrar (SpR) training posts. In Newcastle, the postholder was appointed as a Lecturer in Psychiatry based part-time at the academic department and part-time at the cognitive therapy centre. The centre primarily receives referrals from general practitioners and secondary and tertiary mental health services. A small number of referrals come from other counselling services. Patients must have an Axis I disorder to be accepted for assessment. Referrals are screened by experienced team members to assess both diagnosis and suitability for cognitive therapy.

During the initial period of training in cognitive therapy, the SpR evaluated the characteristics, progress and outcome of the first 20 cases treated. In keeping with the scientist-practitioner approach of cognitive therapy, the effectiveness of the therapist's interventions was tested empirically. The outcome of the first cohort of 10 patients (cases 1-10) was compared with that of the second cohort (cases 11-20) to determine any training effects.

\section{The study \\ Methods}

Patients on the waiting list for cognitive therapy were allocated to the trainee by the trainer. A range of diagnoses and problems were selected to provide the SpR with a broad exposure to cognitive therapy. At the intake interview, Axis I diagnosis was confirmed using DSM-IV criteria (American Psychiatric Association, 1994). Axds II personality disorder was identified using the Revised Version of the Personality Disorder Questionnaire (PDQ-R, Hyler et al, 1988).

At the beginning and end of therapy, patients completed the following self-rated questionnaires: the Beck Depression Inventory (BDI; Beck et al, 1961); the Dysfunctional Attitude Scale (DAS; Weissman, 1979); the Hopelessness Scale (Beck et al, 1974); the Automatic Thought Questionnaire (ATQ: Hollon \& Kendall, 1980) and the State-Trait Anxiety Inventory-State scale (STAI-S; Spielberger et al, 1970). The BDI is a 21-item measure of severity of depression, total scores range from 0-63. The DAS is a 40item measure of underlying beliefs (range 40 280). The Hopelessness Scale is a 20-item measure of hopelessness (range 0-20). The ATQ comprises 30 self-statements frequently associated with depressed mood (range 30-150). The STAI-S instrument comprises 20 statements concerning current severity of anxiety symptoms and thoughts (range 20-80). A higher score on each scale indicates a higher level of symptomatology or dysfunction.

\section{Statistical analysis}

Data were analysed using the Statistical Package for the Social Sciences version 8.0 (SPSS, 1997). Change in scores from baseline to end of therapy was assessed using paired $t$-tests. The effect size (E) for treatment was determined using the formula $\mathrm{E}=\mathrm{C} / \mathrm{s}$.d., where ' $\mathrm{C}$ ' is the mean change in scores on a particular measure and 's.d.' is the standard deviation of the original scores. An effect size of 0.2 is considered small and 0.8 is considered large (Cohen, 1977).

Non-parametric Mann-Whitney U-tests were used to compare the outcomes of the two cohorts. The size of any cohort effect was calculated using the formula $E=D / s$.d., where ' $D$ ' is the difference between the first and second groups in mean change of the measure and s.d. Is the pooled

Table 1. Relationship of diagnosis and dominant personallty disorder cluster in each cohort

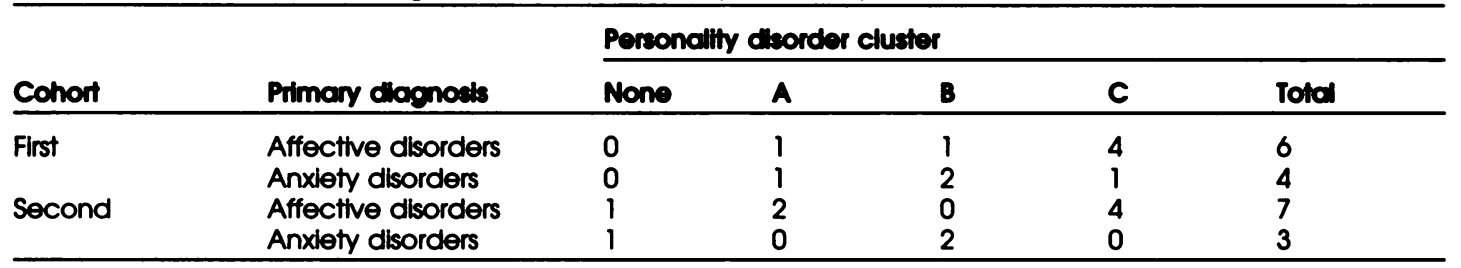

Affective disorders, bipolar disorder, major depressive disorder, dysthymic disorder. Anxiety disorders, obsesstvecompulsive disorder, post-traumatic stress disorder, panic disorder, agoraphobla. 
standard deviation of change (Roth \& Fonagy, 1996). This provides a measure of the relattve improvement in each group for each outcome measure standardised by the standard deviation of the changes. It assumes a normal distribution of the changes in scores. This was confirmed by one-sample Kolmogorov-Smirnov tests.

\section{Findings}

\section{Patient characteristics}

The mean age of the sample was 36.6 years (range 21-53); 12 patients were women. Flve patients had major depresstve disorder and six had dysthymic disorder. All 20 patients demonstrated either Axis I or Axis II comorbidity. Eighteen patients met criteria for at least one personality disorder. Cluster $C$ disorders $(n=9)$ were most common, followed by Cluster B disorders ( $n=6)$ and then Cluster $A$ disorders $(n=3)$.

At the start of therapy, the mean BDI score was 25.4 (range 9-42), the mean DAS score was 156 (range 71-236; the mean Hopelessness Scale score was 13.3 (range 3-20); the mean ATQ score was 93 (range 39-139); and the mean STAI-S score was 60.1 (range 33-77). The median therapy time was 20 hours (range 3-38). Four of the five subjects who did not complete therapy had cluster $B$ personality disorders.

\section{Outcome}

As shown in Table 2, the sample showed a significant change on each psychometric measure following treatment (paired $t$-tests, d.f. $=14$, $P<0.01)$. Effect sizes for treatment ranged from 0.64-1.34. Between group comparisons showed that the median course of therapy in the first cohort was significantly longer than the second cohort (21.5 v. 17.5 hours; Mann-Whitney $U$ test, $P=0.02$ ). The second cohort also showed significantly greater improvements than the first on the BDI (Mann-Whitney U-test, $P=0.05$ ) and ATQ (Mann-Whitney $U$-test, $P=0.03$ ). Effect sizes for differences in improvement between cohorts ranged from -0.14 (DAS) to 1.04 (Hopelessness Scale).

\section{Comment}

Although this is a relatively small sample of patients, the results are of interest. The data demonstrate that most patients benefited from the cognitive therapy offered by the trainee. This is particularly encouraging as all 20 subjects had either axis I or axis II comorbidity. Comorbidity is known to predict poor prognosis in naturalistic studies and to reduce the effectiveness of pharmacotherapy and of short-term symptomfocused therapies such as cognitive therapy

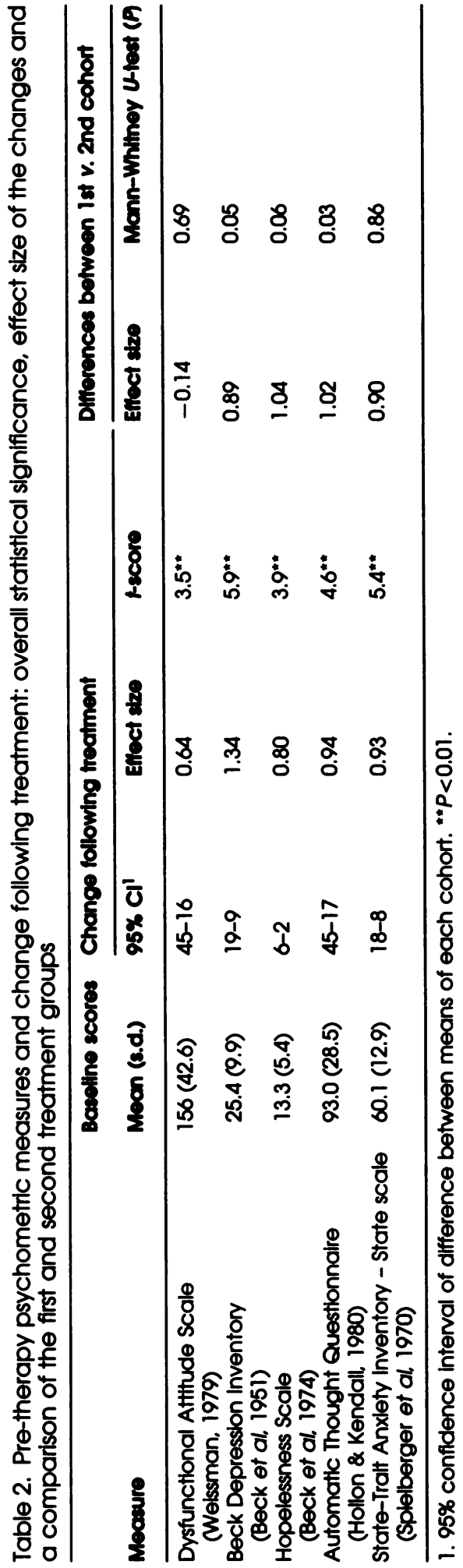


(Elkin et al, 1989; Roth \& Fonagy, 1996). Although it could be argued that the trainee should not take on 'treatment-refractory' cases until a later stage of training, it is important to note that most SpRs already have considerable exposure to cognitive therapy and have often obtained a diploma in cognitive therapy before being appointed to SpR posts. As such, the caseload described reflects the realities of training as a medical specialist in cognitive therapy where the majority of patients are referred because of failure to respond to all other treatments. Few cases reach a psychiatrist simply because they are good candidates for cognitive therapy.

The therapy drop-out rate (25\%) was within the rates reported in outcome studies for pharmacotherapy and psychotherapy (Roth \& Fonagy. 1996). In this study, dropping out of cognitive therapy was associated with the presence of Cluster B personality disorder, rather than cohort membership. It appears that patients with Cluster B personality disorders were more difficult to engage in collaborative work in cognitive therapy. For this reason, it may be appropriate to delay working with this subgroup of patients until a later stage of training, when the SpR is more confident and competent in working with comorbidity. However, it is also important to explore whether this finding is an artefact of the small sample size, a specific difficulty of this trainee or a general problem for cognitive therapy. Roth \& Fonagy (1996) offer some evidence that Cluster B cases do have a worse outcome, but it is unclear if this is a function of early treatment drop-out.

Roth \& Fonagy (1996) note that therapist expertise accounts for $30 \%$ of the variance of outcome in severe and complex cases. This study found that the second cohort of patients showed significantly greater improvement but received significantly fewer cognitive therapy sessions than the first cohort. We believe these results demonstrate the importance of formal and systematic training and supervision in NHS settings. With time the trainee developed more sophisticated formulation skills and also learnt to use therapy sessions more efficiently. It is notable that the greatest effect size was on patients' self-reported hopelessness. The SpR's improved ability to identify and deal with hopelessness when treating the second cohort may go some way to explaining the patients' improved outcome. Instillation of hope is recognised as an important component of many interventions, and Beck et al (1974) have demonstrated that reductions in hopelessness in the early stages of cognitive therapy may be an important 'active' ingredient of this approach.

A significant problem in assessing efficacy of cognitive therapy is clarity in defining therapist experience and training levels (Scott \& Moorhead, 1998). This study examines the relationship between therapist expertise, degree of difficulty of individual cases and clinical effectiveness. A well-conducted study in Newcastle demonstrated clear benefits of training on therapists' technical skills (further details available from the author upon request). The current report provides further evidence that structured and carefully planned training, such as that received by the SpR, may produce significantly improved clinical effectiveness within 12-18 months. It will be important to repeat this evaluation after exposure to 12 months of training in dynamic psychotherapy and also when the trainee works with patients with psychosis and other patients with severe mental disorders.

This evaluation demonstrates the effectiveness of brief therapy in treating patients who have been difficult to treat in other settings. However, the overall success of the College's cognitive therapy training initiative depends on purchasers and providers taking note of this clinical effectiveness data and creating consultant posts in cognitive therapy or other similar brief therapies. To date there has been no increase in the number of such posts advertised.

\section{References}

AMERICAN PSYCHIATRIC AsSOCIATION (1994) Diagnostic and Statistical Manual of Mental Disorders (4th edn) (DSMIV) Washington. DC: American Psychiatric Association. Beck, A. T., WARD, C. H., MENDELSON, M., et al (1961) An inventory for measuring depression. Archives of General Psychiatry, 4, 561-571.

-. WeISsman, A., LESTER, D., et al (1974) The measurement of pessimism: The Hopelessness Scale. Journal of Consulting and Clinical Psychology. 42, 861-865.

COHEN. J. (1977) Statistical Power Analysis for the Behavioural Sciences, revised edition. New York: Academic Press.

Elkin, I., SheA, M. T., Watkins, J. T., et al (1989) National Institute of Mental Health Treatment of Depression Collaborative Program: General effectiveness of treatments. Archives of General Psychiatry. 46. 971-982.

HolloN, S. D. \& KENDAL. P. C. (1980) Cognitive selfstatements in depression: development of the Automatic Thoughts Questionnalre. Cognitive Therapy and Research, 4. 383-395.

HYLE. S. E., RIEDER, R. O.. WILLAMS, J. B. W., et al (1988) The personality and diagnostic questionnaire: development and preliminary results. Joumal of Personality Disorder, 28, 487-503.

RoTh, A. \& FonAGY, P. (1996) What Works for Whom. A Critical Review of Psychotherapy Research. New York: Guilford Press.

SCOTT. J. \& MOORHEAD. S. (1998) Cognitive therapy training for psychiatrists. Advances in Psychiatric Treatment, 4. 3-9.

SPIELBERGER, C. D., GORSUCH, R. L. \& LUSHENE, R. E. (1970) State Trait Anxiety Inventory Manual. Palo Alto, CA: Consulting Psychologists Press Inc.

SPSS (1997) Statistical Package for Social Sciences. Version 8.0. Chicago. IL: SPSS. 
Weissman, A. (1979) Dysfunctional Attitude Scale: A validation study. Dissertation Abstracts International 40. 1389-1390.

*Steve Moorhead, Lecturer in Cognitive Therapy, University Department of Psychiatry, Royal Victoria Infirmary. Newcastle upon Tyne NE1
4LP: and Jan Scott, Head of Division of Psychiatry, University Department of Psychological Medicine, Gartnavel Royal Hospital, Glasgow GL2 OXH

*Correspondence

\title{
Determining whether senior and specialist registrars choose or reject a career in general adult psychiatry
}

\author{
A survey of factors
}

\author{
Mark Davies and Tom Schlich
}

\begin{abstract}
Aims and method Following concerns over recruitment into general adult psychiatry, this study was undertaken to determine which factors influence senior trainees in psychiatry with regard to whether or not they choose a career in general adult psychiatry. The method used was by postal survey of all senior and specialist registrars in the UK.

Results Of those responding, 32.6\% had chosen a career in general adult psychiatry, while $38.9 \%$ had actively rejected such a career. Twenty-six per cent of respondents had chosen another speciality without actively rejecting general adult psychiatry. For those actively rejecting general adult psychiatry, the top three factors cited were poor resources (57.6\%), high workload (43.2\%) and poor working conditions (30.7\%). Clinical implications Through an awareness of why senior trainees reject general adult psychiatry as a possible career, resources can be targeted more specifically in the future at the factors responsible. and thereby improve recruitment into this speciality.
\end{abstract}

Recent reports have highlighted problems with recruitment into general adult psychiatry consultant posts. From 1994 to 1997 the number of vacant posts in general adult psychiatry has risen from 157 (11.1\% of total posts) to 212 (13.2\% of total posts) (Royal College of Psychiatrists, 1997). In addition, many consultants have been retiring early from general adult psychiatry, many for work-related rather than personal reasons (Kendell \& Pearce, 1997). The main source of recruitment into these consultant posts is from senior and specialist registrars in higher psychiatric training. The aim of this study was to determine the factors significant in whether or not senior and specialist registrars choose a career in general adult psychiatry.

\section{The study}

A survey of specialist and senior registrars training in rotations covering all psychiatric specialities in the UK was carried out between November 1997 and May 1998. A list of all scheme organisers for higher psychiatric training was obtained from the Royal College of Psychiatrists. Senior and specialist registrars were contacted through these scheme organisers and asked to complete a questionnaire.

The questionnaire was designed to determine which factors were of relevance in making final career choices. The questionnaire was in two parts; the first part asked trainees their intended career and speciality, for example, consultant in general adult psychiatry. In the second part respondents were asked to indicate which one of three possibilities applied: (a) that they had decided upon a career in general adult psychiatry: (b) that they had actively rejected a career in general adult psychiatry and had chosen another speciality; and (c) that they had always intended to pursue a career in a speciality other than 